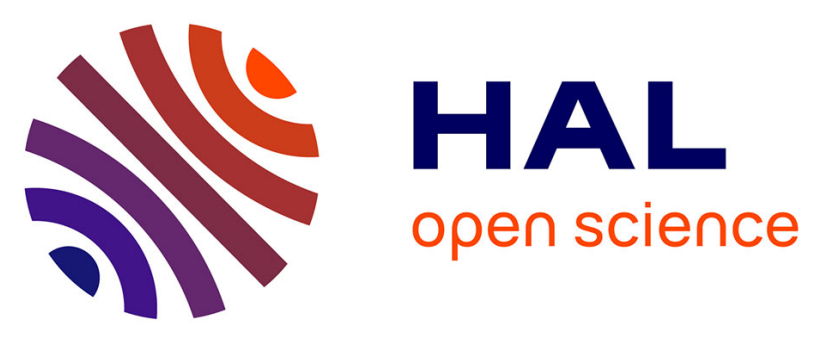

\title{
Phytoextracted mining wastes for ecocatalysis: Eco-Mn®, an efficient and eco-friendly plant-based catalyst for reductive amination of ketones
}

Vincent Escande, Alicia Velati, Claire Garel, Brice-Loïc Renard, Eddy Petit, Claude Grison

\section{To cite this version:}

Vincent Escande, Alicia Velati, Claire Garel, Brice-Loïc Renard, Eddy Petit, et al.. Phytoextracted mining wastes for ecocatalysis: Eco-Mn®, an efficient and eco-friendly plant-based catalyst for reductive amination of ketones. Green Chemistry, 2015, Elemental Recovery and Sustainability, 17 (4), pp.2188 - 2199. 10.1039/C4GC02193B . hal-01937652

\section{HAL Id: hal-01937652 \\ https://hal.umontpellier.fr/hal-01937652}

Submitted on 11 Mar 2021

HAL is a multi-disciplinary open access archive for the deposit and dissemination of scientific research documents, whether they are published or not. The documents may come from teaching and research institutions in France or abroad, or from public or private research centers.
L'archive ouverte pluridisciplinaire HAL, est destinée au dépôt et à la diffusion de documents scientifiques de niveau recherche, publiés ou non, émanant des établissements d'enseignement et de recherche français ou étrangers, des laboratoires publics ou privés. 


\title{
Phytoextracted mining wastes for Ecocatalysis: Eco- $M^{\circledR}$, an efficient and eco-friendly plant-based catalyst for reductive amination of ketones
}

\author{
Vincent Escande, ${ }^{\mathrm{a}}$ Alicia Velati, ${ }^{\mathrm{a}}$ Claire Garel, ${ }^{\mathrm{a}}$ Brice-Loïc Renard, ${ }^{\mathrm{a}}$ Eddy Petit, ${ }^{\mathrm{b}}$ \\ Claude Grison*,a \\ The rehabilitation of contaminated soils from phytoextraction technologies and the chemical recovery of \\ subsequent biomass constitute a new strategy for the recycling of vital minerals required by industrial \\ chemistry. Plant wastes derived from phytoextraction constituted the raw material for the preparation of \\ eco-friendly catalysts for organic synthesis, namely Ecocatalysis. Eco- $\mathrm{Mn}^{\mathbb{B}}$ was thus prepared starting \\ from native plants used for rehabilitation of New Caledonian mining sites. Eco- $\mathrm{Mn}^{\circledR}$ revealed an original \\ polymetallic composition resulting in marked Brønsted and Lewis acidities and displayed superior \\ catalytic performances than classical Mn salts, as highlighted by infrared study of pyridine desorption \\ and model test reactions. The performances of Eco- $\mathrm{Mn}^{\mathbb{B}}$ were illustrated by the reductive amination of \\ ketones, in solvent-free conditions, with the easily prepared and safe Hantzsch ester (HEH) as reducing \\ agent. A beneficial influence of water was observed with a model $\mathrm{MnCl}_{2}$-catalyzed reaction. \\ Investigation of this effect revealed that water was specifically involved in the second step of the \\ reaction, by activating both the imine substrate and the reducing agent. Finally, the Eco-Mn ${ }^{\mathbb{R}} / \mathrm{HEH}$ \\ methodology was applied to the reductive amination of various ketones and amines, giving good yields \\ of products (up to 99\%), including two precursors of pharmaceutical compounds.
}

\section{Introduction}

The sustainable access to elemental supply has become a growing concern in recent years. The global increasing of living standards and the continuous growth of the world population lead to a rapid decreasing of the available reserves of many mineral resources, which will be exhausted in less than 50 years. ${ }^{1,2}$ This situation is particularly critical for some transition metals, such as zinc, nickel, manganese and platinum group elements (PGE), frequently used in industrial processes as catalysts with unique chemical properties. ${ }^{3}$ Chemical requirements for these non-renewable resources are increasing steadily, which explains the diminishing exploitable availability. Because of this phenomenon, elements become notably dispersed in the environment, which results in pollution issues and is a supplementary problem. ${ }^{4}, 5$ In several countries, governmental authorities have decided to develop innovative technologies of recycling, in order to tackle this increasing concern. Numerous efforts are thus devoted to the elaboration of large-scale recycling processes, adapted to low concentrations of elements, present in complex and varied environments. ${ }^{6}$

${ }^{a}$ Laboratoire de Chimie Bio-inspirée et d'Innovations Ecologiques FRE CNRS-UM2 3673, Stratoz-Cap Alpha, Avenue de l'Europe 34830 Clapiers, France

E-mail: claude.grison@cnrs.fr

${ }^{b}$ Institut Européen des Membranes, UMR 5635, CC 047, Place Eugène Bataillon, 34095 Montpellier, France
Promising research areas have recently emerged, such as biomining, a technology that uses microbes to recover metallic elements from ores or wastes. ${ }^{7,8}$ Another example is the recovery of metals from electronic wastes, in particular through the use of plasma technology. ${ }^{9}, 10$ As regards the recovery of metallic elements dispersed in soils, phytoextraction is an effective phytotechnology which relies on the use of so-called metal-hyperaccumulating plants, able to extract metallic elements from the soil and concentrate them in their leaves. ${ }^{11,12}$ Phytoextraction is well appropriate to the treatment of large surfaces of soils where the concentration in metallic trace elements (TE) is too low to be recovered by the classical mining processes in a cost-effective fashion. ${ }^{13-15}$ Moreover, phytoextraction is among the less costly technologies of soils remediation and has a good public acceptance. ${ }^{16}$ It leads to develop a vegetative cover, which forms a protection against wind and water erosion of TE. However, TE concentration is high enough to cause environmental problems and to generate new wastes. ${ }^{17}$ Previous works of our group have led to the emergence of the new concept of Ecocatalysis, which lies on the recovery of metal-hyperaccumulating plants, growing on contaminated and degraded soils, as raw material for the preparation of innovative metallic catalysts for organic synthesis. ${ }^{18-21}$ The concept of Ecocatalysis is thus a novel way of recycling of metallic elements dispersed in soils due to past or present industrial activity, such as mining. Ecocatalysis allows the valorization of problematic and toxic wastes into a novel metallic 
resource for organic chemistry, being thus an opportunity for green chemistry and for the development of a new circular economy (Fig. 1). As Ecocatalysis enables the exploitation of a new resource of metals while contributing to the rehabilitation of polluted and degraded sites, this approach fits fully with the objectives of green chemistry by not only preventing environmental problems, but solving current pollution problems. This concept answers thus to a challenge proposed by P. Anastas and J. C. Warner, since the beginnings of green chemistry. ${ }^{22}$

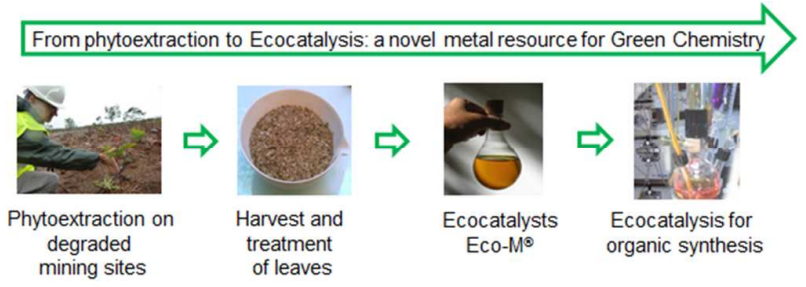

Fig. 1 General concept of transformation of metal-enriched biomass into ecocatalysts

The diversity of metal hyperaccumulating plants and the specificity of phytoextracted metallic elements lead to the original compositions and properties of the ecocatalysts. The resulting ecocatalysts display unusual properties, and often higher than those of the corresponding "classical" metallic salts. ${ }^{23-25}$ In previous reports, we have highlighted the performances in terms of selectivity and efficiency of various ecocatalysts, named $\mathrm{Eco} \mathrm{M}^{\circledR}$ (where $\mathrm{M}$ is the metal predominantly accumulated by the plant), such as Eco- $\mathrm{Zn}^{\circledR}$, Eco$\mathrm{Ni}^{\circledR}, \mathrm{Eco}-\mathrm{Mn}^{\circledR}, \mathrm{Eco}-\mathrm{Cu}^{\circledR} \ldots{ }^{14,26-31}$ These ecocatalysts, as polymetallic catalysts, are thus often active with low catalytic loadings thanks to synergy phenomena between their constitutive metallic elements, with high potential for green chemistry. ${ }^{32}$ This is especially the case for the Eco- $\mathrm{Mn}^{\circledR}$ catalyst, which has demonstrated substantially higher efficiency as catalyst for oxidation reactions and Lewis acid catalyzed reactions, than the commercial Mn simple salts. ${ }^{27}$ This Eco-Mn ${ }^{\circledR}$ catalyst is very promising for applications in green chemistry. The element manganese is non-toxic and among the most abundant transition metals in the Earth's crust. ${ }^{33,} 34$ Whereas manganese has been extensively studied for its properties in oxidation reactions, the activity of its derivatives in Lewis acidcatalyzed reactions has received paradoxically little attention. ${ }^{35-37}$ In the course of our studies of Lewis acid properties of the Eco-Mn ${ }^{\circledR}$ catalyst, we report here its high catalytic efficiency in promoting reductive amination reactions.

Reductive amination gives access to substituted amines by the condensation of a carbonyl compound and an amine, followed by the reduction of the formed imine or iminium. This reaction provides a practical and general way of synthesis of a broad range of building blocks for organic synthesis and of industrially important compounds, such as pharmaceuticals or agrochemicals. ${ }^{38-40}$ Reductive amination requires the use of a reducing agent, which is a delicate question regarding the exigencies of green chemistry, as most of the classical reducing agents are associated with toxicity or safety issues. ${ }^{41,42}$ A typical example is sodium borohydride, widely used in various reduction reactions including reductive amination, ${ }^{43}$ but which is highly toxic and generates sodium borate as by-product, whose reproductive and developmental toxicity is well documented. ${ }^{44,45}$ For such safety reasons, the European Chemicals Agency lists an increasing number of boron derivatives among the substances of very high concern requiring an authorization for their use in industrial processes, according to the European regulation REACH (Registration, Evaluation, Authorization and Restriction of Chemicals). ${ }^{46}$ In the context of evolution of chemistry toward sustainable processes, safe and non-polluting reduction methods are thus highly needed. Hydrogen is one of the greenest reducing agents, often described in reductive amination reactions. ${ }^{38}$ However, its use is not only associated with safety issues but hydrogenation requires also catalysts predominantly based on precious metals such as $\mathrm{Pd}, \mathrm{Pt}$ and $\mathrm{Rh}$, which are rare and highly expensive. Boron hydrides alternative to $\mathrm{NaBH}_{4}$ have also been proposed as reducing agents in reductive amination, such as $\mathrm{NaBH}_{3} \mathrm{CN},{ }^{47} \mathrm{NaBH}(\mathrm{OAc})_{3},{ }^{48}$ Pyridine$\mathrm{BH}_{3},{ }^{49}$ but they are equally associated with toxicity and safety issues. In recent years, greener reducing reagents have been proposed for reductive amination, such as silanes and formates, but they still need catalysts based on rare or toxic metals, or whose manipulation is hazardous. ${ }^{50-53}$ Another method of reductive amination, inspired by biomimetic concepts, implies the use of 1,4dihydropyridines as reducing agents, more particularly the Hantzsch ester (HEH, also named ethidine or diludine), easily prepared in large quantities from affordable reagents. ${ }^{54,55}$ As the Hantzsch ester and its by-product have also the advantage of being non-toxic and safe to manipulate, an abundant literature has been devoted to reductive amination using this reagent with various catalysts, such as $\mathrm{Mg}\left(\mathrm{ClO}_{4}\right)_{2},{ }^{56} \mathrm{ZrCl}_{4},{ }^{57} \mathrm{Sc}(\mathrm{OTf})_{3},{ }^{58}$ gold and silver complexes, ${ }^{59}$ nucleotide model, ${ }^{60}$ chiral phosphoric acids, ${ }^{61-64}$ combined Brønsted acid and transition-metal ${ }^{65}$ and thioureas. ${ }^{66-70}$ Interestingly, in a recent paper researchers from GlaxoSmithKline selected the system $\mathrm{HEH} / \mathrm{Sc}(\mathrm{OTf})_{3}$ as one of the greener reductive amination method for industrial application. ${ }^{71}$ However some of these catalysts were adapted only to the reductive amination of aldehydes. Moreover, regarding the green chemistry exigencies, such catalytic systems have still some limitations, such as their toxicity, their difficulty of preparation or the use of very expensive metals. We show here that Eco-Mn ${ }^{\circledR}$ has a high potential in green reductive amination with $\mathrm{HEH}$, as biosourced catalyst based on a non-toxic and abundant element, in solvent-free conditions, and that this methodology is adapted to the reductive amination of less reactive substrates such as ketones.

\section{Results and discussion}

\section{Catalyst preparation and characterization}

Eco-Mn ${ }^{\circledR}$ was obtained by thermic treatment, followed by treatment with diluted hydrochloric acid, of leaves of Grevillea exul rubiginosa (Proteaceae) a native plant used for phytoremediation of contaminated mining sites in New Caledonia. As shown by ICP-MS study (Table 1), Eco-Mn ${ }^{\circledR}$, obtained under the form of powder, is a polymetallic catalyst with $\mathrm{Mn}$ as the major transition metal. The reproducibility of composition of similar ecocatalysts was studied in a previous article, and showed that the levels of transition elements are only slightly variable between samples derived from different plants of the same species. ${ }^{23}$ In particular, results show the necessity of considering leaves age in the design of sample collection to obtain a constant TE content in batches of Eco-Mn ${ }^{\circledR} .{ }^{15}$ Eco-Mn ${ }^{\circledR}$ was prepared from several batches of G. exul rubiginosa in order to homogenize the content and minimize possible variations in the composition. Updated data on Mn-hyperaccumulating and accumulating plants from New Caledonia have been presented in some recent papers of our group, aimed at producing Eco-Mn ${ }^{\circledR}$ catalyst on industrial scale in view of its commercialization. ${ }^{13,72,73}$ 
Table 1 ICP-MS analysis of Eco-Mn ${ }^{\circledR}$

\begin{tabular}{ll}
\hline Element & $\mathrm{wt} \%( \pm \mathrm{sd})$ \\
\hline $\mathrm{K}$ & $4.32( \pm 0.0076)$ \\
$\mathrm{Mg}$ & $5.26( \pm 0.086)$ \\
$\mathrm{Ca}$ & $10.44( \pm 0.17)$ \\
$\mathrm{Al}$ & $0.24( \pm 0.015)$ \\
$\mathrm{Mn}$ & $6.72( \pm 0.037)$ \\
$\mathrm{Fe}$ & $0.90( \pm 0.0075)$ \\
$\mathrm{Ni}$ & $0.040( \pm 0.00039)$ \\
\hline
\end{tabular}

XRD analysis of Eco-Mn ${ }^{\circledR}$ (Fig. 2) was performed to investigate crystalline species present inside the catalyst. XRD showed unusual polymetallic complexes in Eco- $\mathrm{Mn}^{\circledR}$, mainly $\mathrm{CaSO}_{4}\left(\mathrm{H}_{2} \mathrm{O}\right)_{0.5}$, $\mathrm{CaMg}_{2} \mathrm{Cl}_{6}\left(\mathrm{H}_{2} \mathrm{O}\right)_{12}$ and $\mathrm{KMnCl}_{3} . \mathrm{KMnCl}_{3}$ is a masked form of $\mathrm{MnCl}_{2}$, which also indicates that $\mathrm{Mn}$ is present under the oxidation state $\mathrm{Mn}(\mathrm{II})$. XRD did not reveal the presence of molecules containing $\mathrm{Fe}$ or $\mathrm{Al}$, which were detected by the elemental analysis. This was probably due to the non-crystalline nature of these species within the Eco- $\mathrm{Mn}^{\circledR}$ catalyst. As regards the oxidation state of iron in $\mathrm{Eco}^{-\mathrm{Mn}^{\circledR}}{ }^{\circledR}$ a colorimetric test with ammonium thiocyanate demonstrated that iron was present under the oxidation state $\mathrm{Fe}(\mathrm{III})$ in the catalyst. ${ }^{74}$

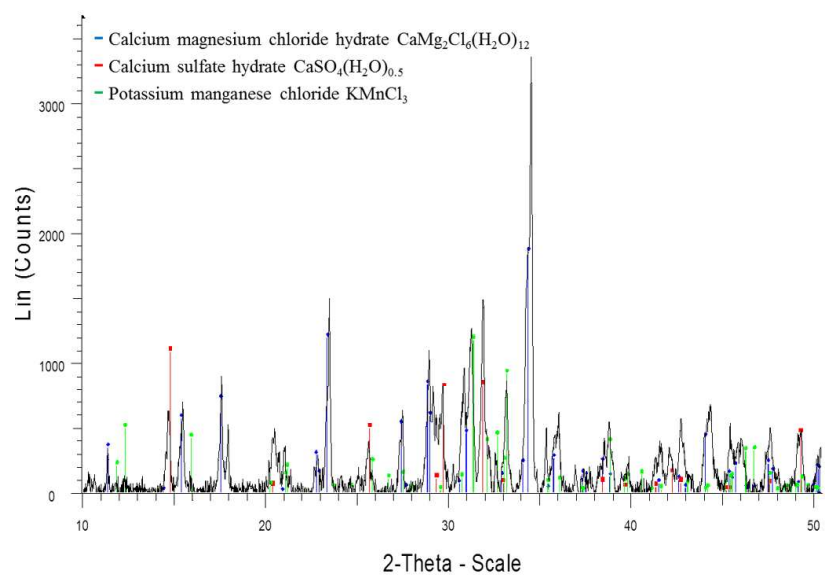

Fig. 2 XRD diffraction pattern of Eco-Mn

According to XRD analysis, Eco-Mn ${ }^{\circledR}$ is made of several Lewis acid complexes, thus its Lewis acid properties might be unusual. Lewis acidity of Eco- $\mathrm{Mn}^{\circledR}$ can be first characterized by its strength. A test reaction, the ene-cyclization of the monoterpene $(+)$-citronellal into isopulegol isomers, was used here to monitor the acidity of Eco-Mn ${ }^{\mathbb{B}}$ catalyst and compare it with commercial manganese chloride catalysts, by discriminating these catalysts according to the strength of their Lewis acidity. Such insight is important to rationally design our ecocatalysts and has been previously applied in the literature to $\mathrm{Cu}$ catalysts via experimental and theoretical approaches. ${ }^{75,76}$ This reaction shows a complex selectivity pattern, as $(+)$-citronellal can be converted to four diastereomers, namely (-)-isopulegol, (+)-isoisopulegol, (+)-neo-isopulegol, and (+)-neoiso-isopulegol (see supporting information scheme S5). The synthesis of (-)-isopulegol as the major isomer in this reaction is well documented. With Lewis acids, high selectivities of (-)-isopulegol can be reached, especially when supported metal halides are used. ${ }^{77}$ The carbonyl bond is activated by the Lewis acid, leading to a transition state which is similar to (-)-isopulegol, yielding the highest positive charge on the carbon of the carbonyl group and favoring therefore the nucleophilic attack of the $\mathrm{C}=\mathrm{C}$ bond. With Brønsted acids, the ratio of (-)isopulegol to the other isomers is usually significantly lower than with Lewis acids, but (-)-isopulegol is still the most abundant isomer. $^{78,79}$ In a previous article on the development of Eco-Mn ${ }^{\circledR}$ catalysis, our group has shown that this plant-based $\mathrm{Mn}(\mathrm{II})$ catalyst was a very efficient catalyst in the carbonyl-ene cyclization of $(+)-$ citronellal into isopulegol (95\% yield with $90 \%$ of (-)-isopulegol with only $2 \mathrm{~mol} \%$ of $\mathrm{Mn}$ in dichloromethane and in $0.5 \mathrm{~h}) .{ }^{27}$ The selectivity is higher with Eco-Mn ${ }^{\circledR}$ than those obtained with other transition metal chlorides described in the literature such as: $\mathrm{ZnCl}_{2}$ supported ${ }^{77}$ or not, $\mathrm{FeCl}_{3}, \mathrm{AlCl}_{3}, \mathrm{SbCl}_{3}, \mathrm{SnCl}_{4}, \mathrm{TiCl}_{4},{ }^{80} \mathrm{CuCl}_{2}{ }^{75}$ (see supporting information Table S5). As none of the multitude of articles related to the ene-cyclization of citronellal refers to manganese-based catalysts, the Lewis activity of Eco-Mn ${ }^{\circledR}$ has been experimentally compared to those of commercial Mn catalysts, such as anhydrous $\mathrm{MnCl}_{2}$ and $\mathrm{MnCl}_{2} \cdot 4 \mathrm{H}_{2} \mathrm{O}$. Whereas the reaction is complete in $0.5 \mathrm{~h}$ at room temperature with $\mathrm{Eco}-\mathrm{Mn}^{\circledR}$, almost no conversion was observed with the classical Mn catalysts even when hard conditions were used (heating in toluene). So this strong Lewis activity of Eco- $\mathrm{Mn}^{\circledR}$ should be due to its unusual polymetallic composition highlighted by ICP-MS analysis (Table 1). Supplementary studies appeared to be essential to evaluate and describe more specifically Lewis acid properties of Eco-Mn ${ }^{\circledR}$.

Thus, these first results were completed by another method: the infrared characterization of adsorbed pyridine on catalysts. Pyridine is widely used as a probe to investigate Lewis and Brønsted acid properties by monitoring its infrared bands in the range of 1400$1660 \mathrm{~cm}^{-1} \cdot{ }^{81,82}$ Infrared spectra of pyridine adsorbed on Eco-Mn ${ }^{\circledR}$ and commercial anhydrous $\mathrm{MnCl}_{2}$ recorded after outgassing at $25^{\circ} \mathrm{C}$ and at $150^{\circ} \mathrm{C}$ are presented in Figure 3 (a study after outgassing at higher temperatures than $150^{\circ} \mathrm{C}$, did not give more useful information). Lewis acidity of Eco- $\mathrm{Mn}^{\circledR}$ was evidenced here by the infrared band at $1446 \mathrm{~cm}^{-1}$ characteristic of pyridine strongly bonded to Lewis acid sites, ${ }^{81,} 82$ observed after outgassing at $25^{\circ} \mathrm{C}$. However, the intensity of this band was strongly reduced after the outgassing at $150^{\circ} \mathrm{C}$, while new infrared bands in the range of 1531 $1537 \mathrm{~cm}^{-1}$ appeared, which are characteristic of pyridinium ion, as well as bands at $1630-1635 \mathrm{~cm}^{-1}$ (but these latter bands are ambiguous as they also might be attributed to pyridine bonded to Lewis acid sites) ${ }^{82}$ This Brønsted acidity is due to the presence of $\mathrm{CaMg}_{2} \mathrm{Cl}_{6}\left(\mathrm{H}_{2} \mathrm{O}\right)_{12}$ in Eco-Mn ${ }^{\circledR}$, highlighted by XRD analysis: water molecules might be responsible for the hydrolysis of Lewis acids in Eco-Mn ${ }^{\circledR}$, especially at high temperature, leading to protons formation and so to a Brønsted acid character. This was proved by comparing the infrared characterization of adsorbed pyridine on pure synthetic $\mathrm{KMnCl}_{3}, \mathrm{CaSO}_{4}\left(\mathrm{H}_{2} \mathrm{O}\right)_{0.5}$ and $\mathrm{CaMg}_{2} \mathrm{Cl}_{6}\left(\mathrm{H}_{2} \mathrm{O}\right)_{12}$, the three salts identified by XRD, which are present in Eco- $\mathrm{Mn}^{\circledR}$ (see supporting information Fig. S7). Only $\mathrm{CaMg}_{2} \mathrm{Cl}_{6}\left(\mathrm{H}_{2} \mathrm{O}\right)_{12}$ displayed Brønsted acid character, and is thus responsible for the Brønsted acidity observed with Eco- $\mathrm{Mn}^{\circledR}$. Thus after outgassing at $150^{\circ} \mathrm{C}$, the Lewis acids were mainly hydrolyzed and only pyridinium ion became visible. The infrared spectrum of adsorbed pyridine on the mixture of the three salts present in Eco-Mn ${ }^{\circledR}$ was really closed to the spectrum observed with Eco-Mn ${ }^{\circledR}$ (Fig. 3), which showed that these salts are mainly responsible for the Lewis and Brønsted acid properties of Eco-Mn ${ }^{\circledR}$. 

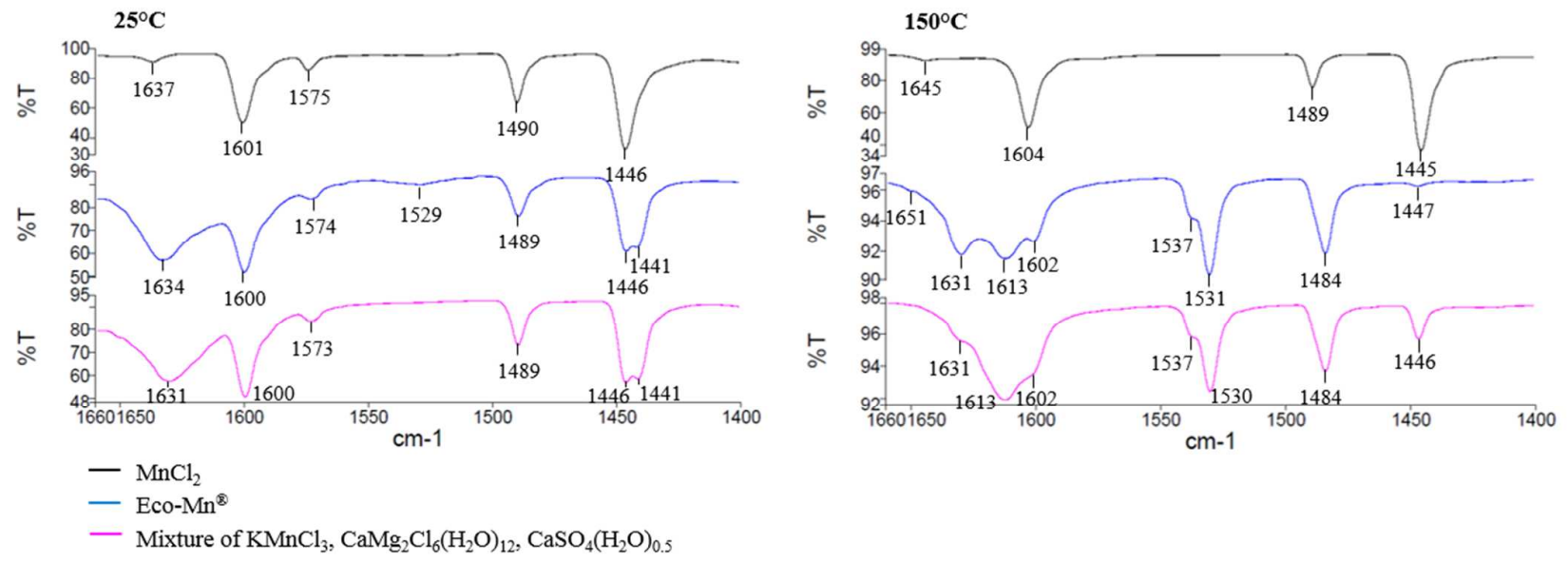

Figure 3 IR spectra of pyridine adsorbed on Eco- $\mathrm{Mn}^{\circledR}$ and on commercial or synthetic salts constitutive of Eco-Mn ${ }^{\circledR}$, recorded after outgassing at $25^{\circ} \mathrm{C}$ and $150^{\circ} \mathrm{C}$

Conclusions obtained both with the synthesis of isopulegol and with the infrared characterization of adsorbed pyridine were supported and completed by using a third method, implemented and tested by Corma et al., ${ }^{83,84}$ which consists in studying the rearrangement pathway of the cyclic acetal of $\alpha$-bromopropiophenone in the presence of catalysts. By studying the selectivity of products, the hardness of the Lewis acidity (according to HSAB principle ${ }^{85,86}$ ) of different catalysts can be assessed and compared. According to conversion rates (see supporting information Table S9), Eco- $\mathrm{Mn}^{\mathbb{R}}$ is more active than commercial manganese chlorides on cyclic acetal, which well supports results obtained with the synthesis of isopulegol, about the strength of the Lewis acidity of Eco-Mn ${ }^{\circledR}$. The Brønsted acidity of Eco-Mn ${ }^{\circledR}$ was also shown by this method, which confirmed the infrared study of adsorbed pyridine. The high selectivity of products from the Brønsted acid pathway indicated that commercial $\mathrm{MnCl}_{2} \cdot 4 \mathrm{H}_{2} \mathrm{O}$ generates a stronger Brønsted acid character than anhydrous $\mathrm{MnCl}_{2}$ in the reaction conditions. This corroborates the hypothesis formulated previously about the role of water molecules in hydrolysis of metal chlorides and in appearance of a Brønsted acid character. Finally, this method revealed that Lewis acidity of Eco- $\mathrm{Mn}^{\circledR}$ is harder than the one of commercial manganese chlorides, which are considered as hard Lewis acids by HSAB theory. ${ }^{87}$ The higher hardness of Lewis acid sites of Eco-Mn ${ }^{\circledR}$ probably results from the presence of additional elements such as calcium or magnesium highlighted by ICP-MS analysis (Table 1), which are known to be hard Lewis acids. ${ }^{87}$

\section{Reductive amination with Hantzsch ester catalyzed by Eco- $\mathrm{Mn}^{\circledR}$}

\subsection{Reductive amination of ketones}

The selected reducing agent, HEH was synthesized following a known procedure, by simply refluxing paraformaldehyde, ethyl acetoacetate and ammonium acetate in water for 2 hours, without the need for any catalyst. ${ }^{88} \mathrm{HEH}$ was thus obtained with $87 \%$ yield (Scheme 1). The product was collected by filtration and was of sufficient purity to be used without further purification. We however observed that it was preferable to prepare HEH in the dark, as this 1,4-dihydropyridine is somewhat light-sensitive. ${ }^{89}$

Scheme 1 Chromatography-free preparation of HEH in water

We began our study by verifying that the reductive amination of aldehydes by $\mathrm{HEH}$ does not need any catalyst when performed in solvent-free conditions. However, when applied to ketones, the same reaction was sluggish and limited to the more reactive substrates, affording satisfactory yields only after 24 to 48 hours, at $150^{\circ} \mathrm{C} .^{90}$ This was a clear indication that a catalyst was desirable to perform the solvent-free reductive amination of ketones with $\mathrm{HEH}$, with moderate heating and in reasonable reaction time. Our first attempts involving cyclohexanone 1a and aniline 2a showed that Eco-Mn ${ }^{\circledR}$ catalyst dramatically accelerated the reaction, as the product $\mathbf{3 a}$ was obtained in $96 \%$ yield, after only 1 hour at $80^{\circ} \mathrm{C}$. Eco-Mn ${ }^{\circledR}$ was remarkably efficient, as it was possible to lower the catalytic loading to $0.25 \mathrm{~mol} \%$, without affecting its performances (Table 2, entry 3 ). A blank test clearly indicated that the reaction was not possible without catalyst in the selected conditions (Table 2, entry 1 ). In order to place these results in context, a comparison was made with previously described methods of reductive amination on the same substrates (Table 2, entries 4-11). This overview of various reducing agents and catalysts highlighted the advantages of the proposed methodology, avoiding the use of toxic reagents and of rare and expensive metals as catalysts. Moreover, the high catalytic loadings, harmful conditions and long reaction times, often used whereas they are not compatible with green chemistry exigencies, are not necessary with the Eco-Mn ${ }^{\circledR} / \mathrm{HEH}$ methodology. The catalytic efficiency of the Eco- $\mathrm{Mn}^{\circledR}$ catalyst was compared to classical Mn salts, under the form of chlorides, which are the majority anions in the plant-based Eco-Mn ${ }^{\circledR}$. In order to better highlight the differences between the catalysts, the reaction was performed on the less reactive 3-methyl-2-butanone $\mathbf{1 b}$. Reaction conditions were adjusted to $1 \mathrm{~mol} \%$ of $\mathrm{Mn}, 110^{\circ} \mathrm{C}, 4 \mathrm{~h}$, to observe a sufficient conversion with all the tested $\mathrm{Mn}$ salts. In these conditions, fair yields of product 3b were obtained with commercial Mn chlorides, which confirmed that the activity of Eco- $\mathrm{Mn}^{\circledR}$ was due to its Mn content 
(Table 3, entries 1-3). However, Eco-Mn ${ }^{\circledR}$ conducted to significantly higher conversion than commercial Mn chlorides, illustrating the original properties of the polymetallic complexes in the plant-based catalyst. Our previous IR/pyridine study (section 1. "Catalyst preparation and characterization") of the synthetic mixture of $\mathrm{KMnCl}_{3}, \mathrm{CaSO}_{4}\left(\mathrm{H}_{2} \mathrm{O}\right)_{0.5}$ and $\mathrm{CaMg}_{2} \mathrm{Cl}_{6}\left(\mathrm{H}_{2} \mathrm{O}\right)_{12}$ showed nearly the same pattern than Eco-Mn ${ }^{\mathbb{B}}$, suggesting that the mixture should have the same catalytic properties. However, the synthetic mixture proved to be extremely hygroscopic and practically impossible to use in the same conditions than Eco- $\mathrm{Mn}^{\circledR}$. An attempt of reaction of reductive amination with the synthetic mixture did not give any results, probably for this reason. This extremely hygroscopic character may be attributed to $\mathrm{CaMg}_{2} \mathrm{Cl}_{6}\left(\mathrm{H}_{2} \mathrm{O}\right)_{12}$ which is described in those terms in several papers. ${ }^{91}$ As Eco- $\mathrm{Mn}^{\mathbb{B}}$ did not display such properties and can be manipulated without anhydrous atmosphere, its stability may be due to particular structure of its constituents or to other species not identified yet. This was confirmed by a test with a "reconstituted" Eco-Mn ${ }^{\circledR}$, prepared by mixing commercial chlorides of $\mathrm{K}, \mathrm{Mg}, \mathrm{Ca}, \mathrm{Al}, \mathrm{Mn}, \mathrm{Fe}$ and $\mathrm{Ni}$, in the same proportions than in
Eco-Mn $^{\circledR}$, following its ICP-MS analysis (Table 1). The same yield than with sole $\mathrm{MnCl}_{2} \cdot 4 \mathrm{H}_{2} \mathrm{O}$ was obtained (62\%, Table 3, entries 34 ), which is slightly inferior to the value obtained with the plantbased Eco- $\mathrm{Mn}^{\circledR}(67 \%$, Table 3, entry 1). This showed that the catalytic performances of plant-based Eco- $\mathrm{Mn}^{\mathbb{B}}$ are specific to its particular polymetallic associations, and cannot be explained by a simple sum of activities of classical metal chlorides. Interestingly, a noticeable difference in conversion was observed between anhydrous $\mathrm{MnCl}_{2}$ (3b yield: $49 \%$ ) and $\mathrm{MnCl}_{2} \cdot 4 \mathrm{H}_{2} \mathrm{O}$ (3b yield: $62 \%$ ), which indicated that the presence of water seemed beneficial for the reaction. This result was counter-intuitive since following the mechanism of reductive amination, the presence of water is unfavorable to the formation of the imine in the first step of the reaction. However, our previous characterization of the catalytic activity of $\mathrm{MnCl}_{2} \cdot 4 \mathrm{H}_{2} \mathrm{O}$ in the rearrangement and hydrolysis of ethylene acetal of 2-bromopropiophenone indicated that this salt demonstrates a marked Brønsted acidity, probably because of a partial hydrolysis of $\mathrm{MnCl}_{2}$, forming $\mathrm{Mn}$ hydroxides and protons (see supporting information S9).

Table 2 Reductive amination of cyclohexanone with aniline catalyzed Eco- $\mathrm{Mn}^{\circledR}$ and comparison to previously published methods

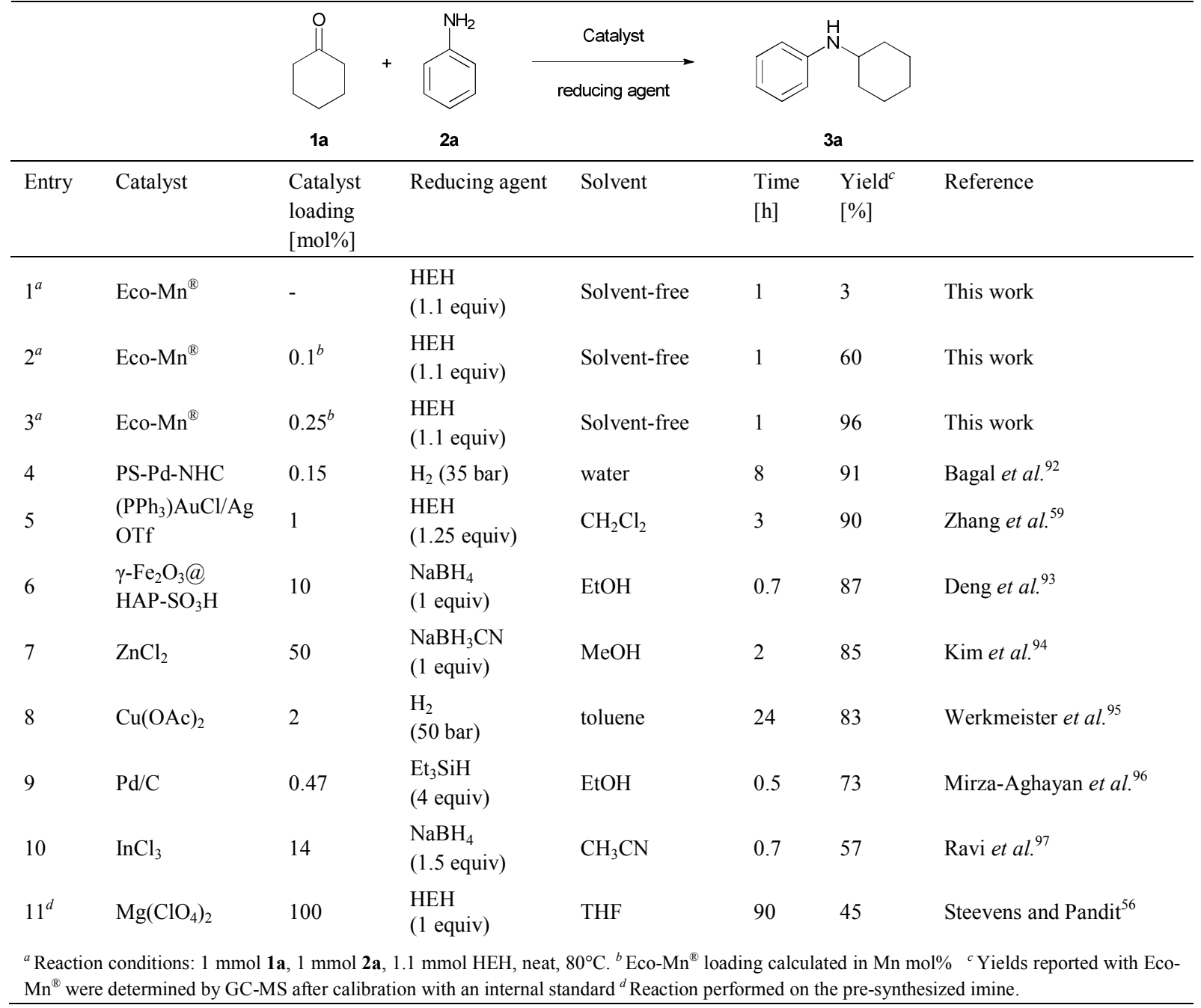


Following this reasoning, the simultaneous presence of water and $\mathrm{MnCl}_{2}$ could become an advantage, since the formed protons could catalyzed the formation of imine and, by protonating it, they could favored its reduction thanks to electrophilic activation. We tested this hypothesis by using as catalyst a mixture of anhydrous $\mathrm{MnCl}_{2}$ and $\mathrm{HCl}_{(\mathrm{aq})}$ (1 mol\% of both species) in order to reproduce the simultaneous Lewis and Brønsted acidity assumed with $\mathrm{MnCl}_{2} \cdot 4 \mathrm{H}_{2} \mathrm{O}$ (Table 3, entry 5). Interestingly, the conversion was indeed higher (55\% yield) than with the sole anhydrous $\mathrm{MnCl}_{2}$ (49\% yield), whereas being slightly lower than with $\mathrm{MnCl}_{2} \cdot 4 \mathrm{H}_{2} \mathrm{O}(62 \%)$. In order to determine if this difference can be explained by another effect of water on the reaction mechanism, we decided to investigate the influence of the amount of water, starting with anhydrous $\mathrm{MnCl}_{2}$.

Table 3 Comparison of Eco- $\mathrm{Mn}^{\circledR}$ and classical Mn chlorides in the reaction

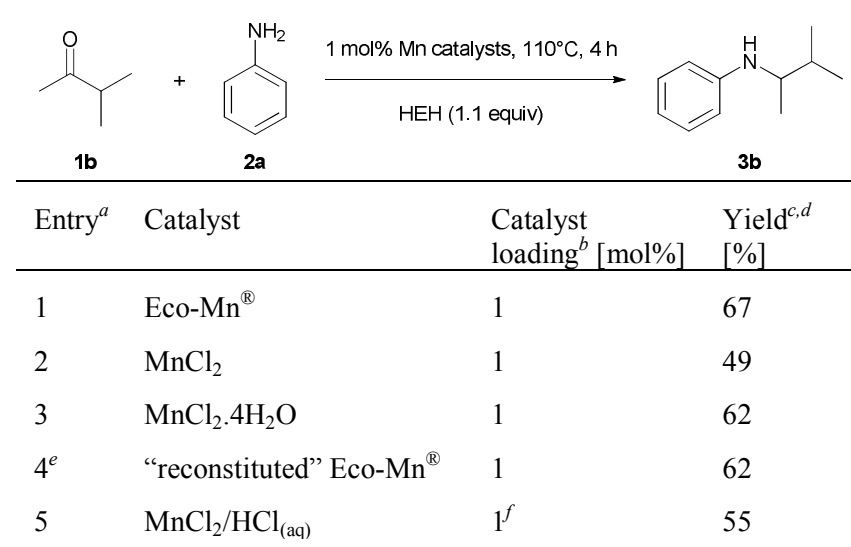

${ }^{a}$ Reaction conditions: $1 \mathrm{mmol} \mathbf{1 b}, 1 \mathrm{mmol} \mathbf{2 a}, 1.1 \mathrm{mmol} \mathrm{HEH}$, neat, $110^{\circ} \mathrm{C}, 4$ h. ${ }^{b}$ Eco-Mn ${ }^{\circledR}$ and "reconstituted" Eco-Mn ${ }^{\circledR}$ loadings calculated in $\mathrm{Mn} \mathrm{mol} \%$. ${ }^{c}$ Yields determined by GC-MS after calibration with an internal standard. ${ }^{d}$ In all cases, less than $5 \%$ of residual imine were detected. ${ }^{\text {e }}$ Reconstituted" Eco$\mathrm{Mn}^{\circledR}$ prepared by mixing commercial chlorides of $\mathrm{K}, \mathrm{Mg}, \mathrm{Ca}, \mathrm{Al}, \mathrm{Mn}, \mathrm{Fe}$ and $\mathrm{Ni}$, in the same proportions than in Eco-Mn ${ }^{\circledR}$, following its ICP-MS analysis. ${ }^{f} 0.83 \mu \mathrm{L}$ of $12 \mathrm{M} \mathrm{HCl}_{(\text {aq) }}$ were added $(1 \mathrm{~mol} \%$ of $\mathrm{HCl})$.

\subsection{Influence of water on the $\mathrm{MnCl}_{2} / \mathrm{HEH}$ reductive amination of ketones}

The reaction was thus performed with anhydrous $\mathrm{MnCl}_{2}$ with increasing amounts of water (Fig. 4). Starting with a yield of $49 \%$ in anhydrous conditions, an optimum was reached when $10 \mathrm{~mol} \%$ of water was added, giving $59 \%$ yield. Higher amounts of water led to a marked decrease of the conversion, probably because the excess of water became too unfavorable for the imine formation. Characterization of $\mathrm{MnCl}_{2}$ hydrated by controlled addition of water (in 1:10 proportions, following the optimized reaction conditions) was attempted by infrared study of pyridine desorption and model test reactions described above (section 1. "Catalyst preparation and characterization"). However, hydrated $\mathrm{MnCl}_{2}$ in these conditions displayed only a slightly higher Brønsted acidity than anhydrous $\mathrm{MnCl}_{2}$ (see supporting information S9). To better understand if the addition of water specifically favored the first step of imine synthesis or its reduction by HEH (the second step), we decided to study these two reactions separately. The influence of $\mathrm{MnCl}_{2}$ and $\mathrm{H}_{2} \mathrm{O}$ was first examined on the formation of imine $\mathbf{4 a}$, by reacting 3methyl-2-butanone $\mathbf{1 b}$ with aniline $\mathbf{2 a}$, without addition of the reducing agent, HEH (Table 4). The obtained results showed that the addition of water seemed to have no overall effect on the imine formation, since the same yield of $\mathbf{4 a}(30 \%)$ was obtained with anhydrous $\mathrm{MnCl}_{2}, \mathrm{MnCl}_{2}$ plus $10 \mathrm{~mol} \%$ of water, and with Eco$\mathrm{Mn}^{\circledR}$. Such observation can be the result of two opposite effects of the addition of water, which on the one side promoted the reaction thanks to the formation of protons by $\mathrm{MnCl}_{2}$ hydrolysis, but on the other side, which also prevented the imine formation, since water is a product of the reaction. The overall observation suggested that these two effects canceled each other out. It is therefore likely that the beneficial effect of the addition of water relates to the second step of the reaction, namely the reduction of the formed imine. However, imine 4a proved to be quite unstable and difficult to isolate, therefore it was not possible to obtain experimental results demonstrating a definite effect of water on its reduction by HEH. We thus envisioned investigating the influence of water on the reduction step by following not the imine, but the transformation of the reducing agent. Indeed, previous studies reported that several reduction reactions using $\mathrm{HEH}$ or similar 1,4-dihydropyridines were significantly accelerated in presence of water. ${ }^{98-100}$ The most frequent explanation proposed for this observation is an activation of the substrate by hydrogen bond formation, stabilizing the transition state. It was equally possible that the water addition contributed to increasing the reactivity of the reducing agent $\mathrm{HEH}$, by favoring its oxidation and thus the substrate reduction, namely the imine.

Table 4 Influence of the addition of water on the first step of the reaction

\begin{tabular}{llll} 
& & & \\
Entry $^{a}$ & Catalyst $^{b}$ & $\begin{array}{l}\text { Added water } \\
{[\text { mol\%] }}\end{array}$ & $\begin{array}{l}\mathrm{Yield}^{c} \\
{[\%]}\end{array}$ \\
\hline 1 & $\mathrm{MnCl}_{2}$ & - & 30 \\
2 & $\mathrm{MnCl}_{2}$ & 10 & 30 \\
3 & $\mathrm{Eco}^{2} \mathrm{Mn}^{\circledR}$ & - & 30
\end{tabular}

${ }^{a}$ Reaction conditions: $1 \mathrm{mmol} \mathbf{1 b}, 1 \mathrm{mmol} \mathrm{2a}, 1 \mathrm{~mol} \%$ Mn-catalyst, neat $110^{\circ} \mathrm{C}, 1 \mathrm{~h} .{ }^{b} \mathrm{Eco}-\mathrm{Mn}^{\mathbb{B}}$ loading calculated in $\mathrm{Mn}$ mol\%. ${ }^{c}$ Yields determined by GC-MS after calibration with an internal standard.

We thus studied the combined effect of water and Mn catalysts on HEH activation, whose oxidation was followed in the conditions of the reductive amination, but in contact with air as oxidizing reagent (Scheme 2 and Fig. 5). After heating $\mathrm{HEH}$ for 1 hour at $110^{\circ} \mathrm{C}$ in open reactor, only $16 \%$ of pyridine resulting of the oxidation was observed. The addition of $10 \mathrm{~mol} \%$ of water slightly increased this proportion to $20 \%$. A more marked effect was observed when anhydrous $\mathrm{MnCl}_{2}$ or Eco- $\mathrm{Mn}^{\circledR}$ were added, resulting respectively in $46 \%$ and $50 \%$ of oxidation product.

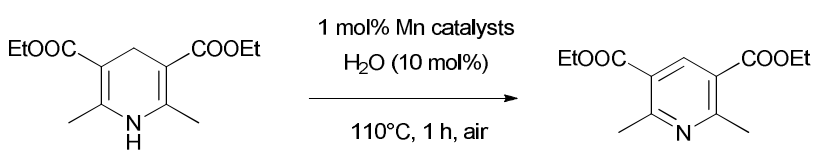

Scheme 2 Model oxidation of HEH by air, catalyzed by Mn-based catalysts in presence of water 
- Yield of 3b (\%)

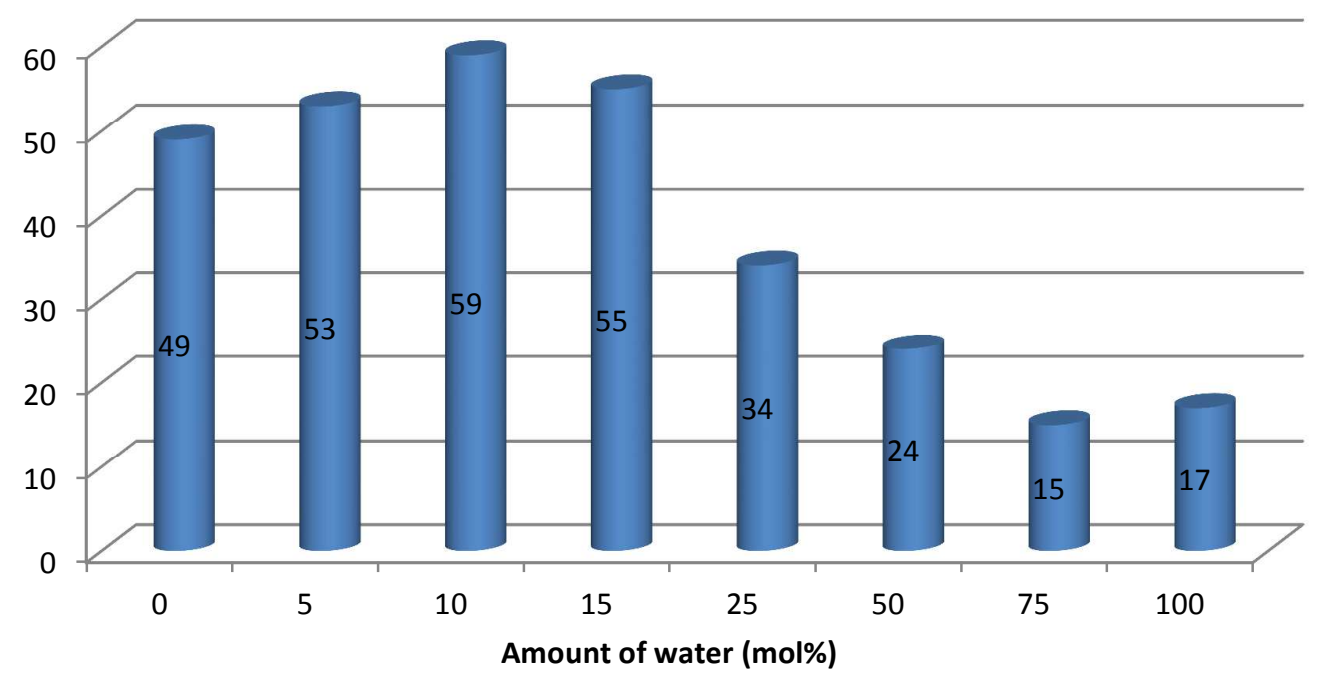

Fig. 4 Influence of the amount of water on the $\mathrm{MnCl}_{2} / \mathrm{HEH}$ reductive amination of ketones

The maximum proportion of pyridine $(58 \%)$ was obtained when $\mathrm{HEH}$ was heated in presence of $\mathrm{MnCl}_{2}(1 \mathrm{~mol} \%)$ and water $(10$ mol\%), the same conditions that used for reductive amination. This result confirmed that the addition of water, in presence of $\mathrm{Mn}$ chloride, played a role in the activation of $\mathrm{HEH}$, which became thus more reactive toward the substrate subjected to reduction. Water has thus probably a beneficial effect specifically on the reduction step of the reaction, for two reasons: first, probably by forming hydrogen bonds or by protonating the imine which thus become more electrophilic, and secondly by activating $\mathrm{HEH}$, and thus fostering its oxidation by the preformed imine.
Since Eco-Mn ${ }^{\circledR}$ demonstrated the higher efficiency in catalyzing the reductive amination of 3-methyl-2-butanone $\mathbf{1 b}$ and aniline $\mathbf{2 a}(67 \%$, Table 3, entry 1 ), addition of water to Eco-Mn ${ }^{\circledR}$ could have increased its efficiency, as revealed for $\mathrm{MnCl}_{2}$. However, such effect was not observed: the yield of $\mathbf{3 b}$ was quite unchanged, probably because Eco-Mn ${ }^{\circledR}$ was already sufficiently hydrated, as shown by XRD (see Fig. 2) or by infrared characterization of the solid powder (an intense band at $3400 \mathrm{~cm}^{-1}$, characteristic of water was observed for Eco$\left.\mathrm{Mn}^{\circledR}\right)$.<smiles>CCOC(=O)c1cc(C(=O)OCC)c(CC)nc1CC</smiles><smiles></smiles>

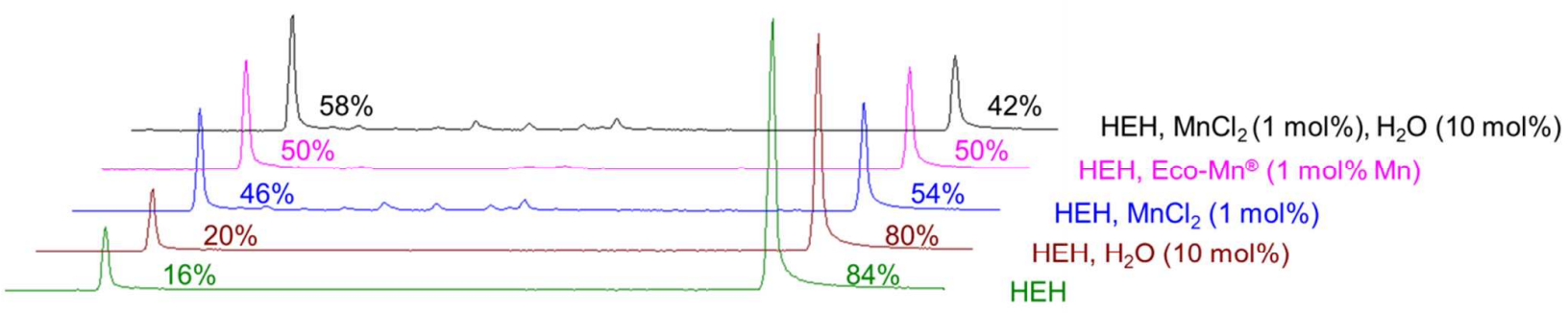

Fig. 5 Comparison of GC-MS chromatograms obtained with various catalysts and water amounts, after heating of $\mathrm{HEH}$ to $110^{\circ} \mathrm{C}, 1 \mathrm{~h}$, in contact with air. 


\subsection{Scope of the methodology}

In order to prove the applicability of the Eco- $\mathrm{Mn}^{\mathbb{R}} / \mathrm{HEH}$ methodology, several ketones and amines were submitted to the previous reaction conditions (Table 5). The different ketones tested (aliphatic or cyclic ketones 1a-c and acetophenone 1d) provided good yields when reacted with aniline 2a (67-97\%, Table 5, entries 1-2 and Table 3, entry 1). Aliphatic and cyclic amines $\mathbf{2 b - c}$ can also be reacted with these ketones, affording very good yields of products 3e-h (88-96\%, Table 5, entries 3-6). Both anilines with electronwithdrawing and electron-donating groups afforded the desired products, in good yields with cyclic ketone 1a (95-99\%, Table 5, entries $7,9,11)$, whereas the yields were moderate on aliphatic ketone $\mathbf{1 b}$, less reactive $(38-67 \%$, Table 5 , entries $8,10,12)$.

Table 5 Reductive amination of different ketones and amines by the Eco-Mn ${ }^{\circledR} / \mathrm{HEH}$ methodology

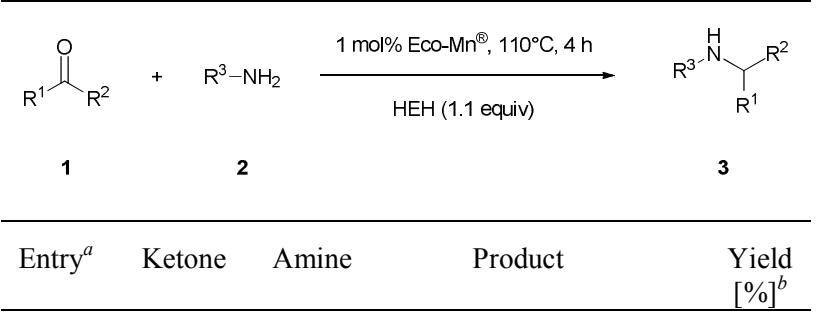

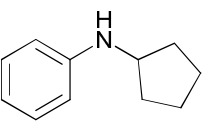

1<smiles>Nc1ccccc1</smiles>

2a

$3 \mathrm{c}$

2<smiles>CC(=O)c1ccccc1</smiles>

2a<smiles>CC(Nc1ccccc1)c1ccccc1</smiles>

3d<smiles>O=C1CCCCC1</smiles>

$1 \mathbf{a}$<smiles>CC(=O)C(C)C</smiles>

2b

1b

$1 \mathrm{a}$<smiles>CCCCN</smiles><smiles>CCCCNC1CCCCC1</smiles>

$2 b$

$3 e$

5<smiles>C1COCCN1</smiles>

2c

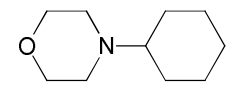

$3 g$

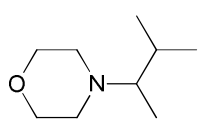

3h
10

7

$1 \mathbf{a}$<smiles>Nc1ccc(F)cc1</smiles>

2d

$1 b$

2d<smiles>Fc1ccc(NC2CCCCC2)cc1</smiles>

8<smiles>CC(C)C(C)Nc1ccc(F)cc1</smiles>

51

3j

9

$1 \mathrm{a}$<smiles>COc1ccc(N)cc1</smiles><smiles>COc1ccc(NC2CCCCC2)cc1</smiles>

$2 \mathrm{e}$

3k

1b<smiles>COc1ccc(NC(C)C(C)C)cc1</smiles>

$1 \mathbf{a}$<smiles>Cc1ccc(N)cc1</smiles><smiles>Cc1ccc(NC2CCCCC2)cc1</smiles>

$2 f$

$3 \mathrm{~m}$

12

$1 b$

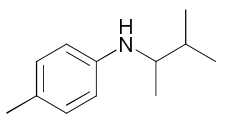

67

3n
${ }^{a}$ Reaction conditions: $1 \mathrm{mmol}$ ketone, $1 \mathrm{mmol}$ amine, $1.1 \mathrm{mmol} \mathrm{HEH}, 1$ mol\% Eco- $\mathrm{Mn}^{\mathbb{R}}$ (calculated in $\mathrm{Mn}$ mol\%), neat, $110^{\circ} \mathrm{C}, 4 \mathrm{~h} .{ }^{b}$ Yields determined by GC-MS after calibration with an internal standard. Values between parentheses are isolated yields (flash chromatography).

The presence of cations from Eco-Mn ${ }^{\circledR}$ has been studied in the products of reaction, by ICP-MS analysis. This investigation showed that only traces of $\mathrm{K}, \mathrm{Mg}, \mathrm{Ca}$ and $\mathrm{Al}$ were detected in the final purified products, with contents inferior to $510 \mathrm{ppm}$ (maximum detected value, for $\mathrm{Ca}$ ). Other metallic elements were present in quantities inferior to $5 \mathrm{ppm}$ (see supporting information S13).

Finally, it was of interest to apply the presented methodology to the preparation of compounds of known interest. We thus selected the synthesis of secondary amines deriving from 2-tetralone and 2indanone, as precursors of pharmaceutical compounds. Compound 30 has been signaled as a pharmacophore of antifungal agents, since it inhibits fungal CYP51, a member of the cytochrome P450 superfamily. ${ }^{101}$ This compound was also reported to be the characteristic skeleton of dermal anesthetic drugs. ${ }^{102}$ Aminoindane compounds such as $\mathbf{3 p}$ have been studied as precursors of cationic sodium channel blockers implied in the activity of nociceptor neurons, in treating pain. ${ }^{103}$ 

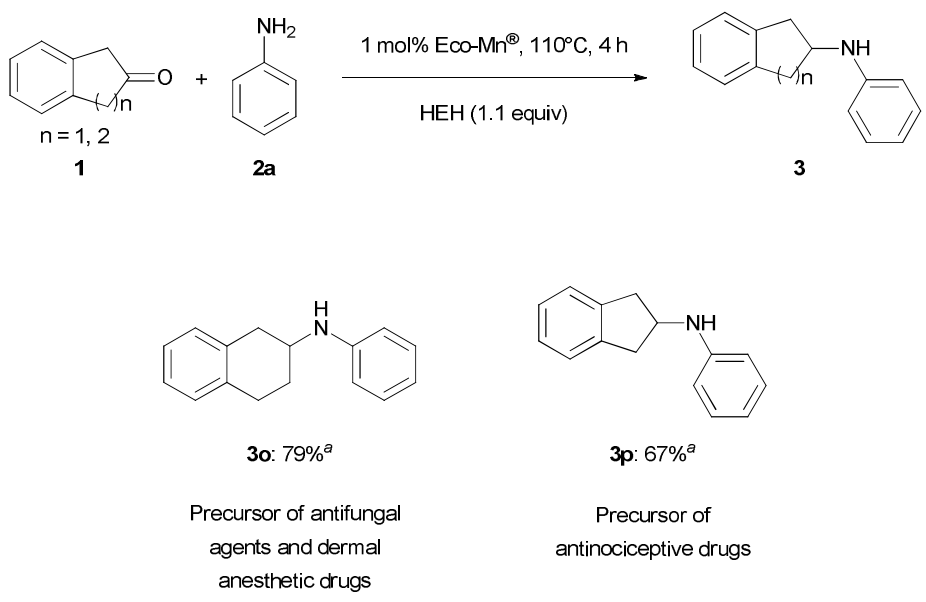

( ${ }^{a}$ isolated yield on $1 \mathrm{~g}$ scale)

Fig. 6 Application of the proposed methodology to the preparation of precursors of pharmaceutical compounds

By applying the proposed Eco-Mn ${ }^{\circledR} / \mathrm{HEH}$ methodology, both compounds were synthesized on $1 \mathrm{~g}$ scale, in good yields (67 and $79 \%$, Figure 6).

\section{Conclusion}

In conclusion, we have shown that pioneer plants used in the mining soil rehabilitation can be recovered as raw material for the production of ecocatalysts. This concept allows to turn wastes derived from phytoextraction into a mineral and sustainable resource for an eco-friendly and innovative organic synthesis. Eco-Mn ${ }^{\circledR}$ was thus prepared from plants growing in New Caledonia, on Mn-rich degraded soils. The catalyst was successfully employed in the reductive amination of ketones, with $\mathrm{HEH}$ as an affordable, safe and easily prepared reducing agent, in a solvent-free methodology and in short reaction times (1-4 h). Eco-Mn ${ }^{\circledR}$ showed a high catalytic efficiency, since a $96 \%$ yield of product can be obtained with only $0.25 \mathrm{~mol} \%$ of catalyst, on the model reaction between cyclohexanone and aniline. Comparison with commercial chlorides of $\mathrm{Mn}$ and others elements present in Eco- $\mathrm{Mn}^{\mathbb{B}}$ demonstrated that its activity was due to the original polymetallic complexes of the plantbased catalyst. Addition of small amounts of water (optimized to 10 mol\%) to model salt $\mathrm{MnCl}_{2}$ revealed to be beneficial for the reductive amination of ketones. Investigation showed that this effect was probably the result of hydrogen bonding or protonation of the pre-formed imine and of HEH activation, becoming more reactive toward the substrate. Finally, the methodology was extended to various starting ketones and amines, illustrating its potential and scope for the synthesis of substituted amines, including precursors of pharmaceutical compounds. Current studies are in progress to perform the reaction with solid supported Eco-Mn ${ }^{\circledR}$, allowing the recycling of the catalyst.

\section{Experimental section}

\section{Reagents and methods}

Reagents and solvents were purchased from Sigma-Aldrich, and were used without further purification. Flash column chromatography was performed using Chromagel Carlo Erba Reactifs SDS silica 60 A CC 35- $70 \mu \mathrm{m}$. Reactions were monitored using Merck Kieselgel 60 F254 aluminum. TLCs were visualized by UV fluorescence $(254 \mathrm{~nm})$ then by immersion in one of the following dyeing reagents: $\mathrm{KMnO}_{4}$, vanillin, ninhydrin, phosphomolybdic acid solution, and phosphotungstic acid solution. NMR spectra were recorded on a Brüker Avance 300 spectrometer at room temperature, ${ }^{1} \mathrm{H}$ frequency is at $300 \mathrm{MHz}$ and ${ }^{13} \mathrm{C}$ frequency is at $75 \mathrm{MHz}$. IR spectra were recorded on a PerkinElmer Spectrum 100 FT-IR spectrometer, in ATR mode. GC-MS analyses were performed on a Shimadzu QP2010SE apparatus, equipped with a 30 $\mathrm{m} \times 0.25 \mathrm{~mm} \times 0.25 \mu \mathrm{m}$ ZB-5MSi Guardian column $\left(\right.$ Phenomenex ${ }^{\circledR}$ ) with hydrogen as carrier gas.

\section{Preparation of Eco-Mn ${ }^{\circledR}$}

Eco- $\mathrm{Mn}^{\circledR}$ was prepared from harvested leaves of Grevillea exul rubiginosa, a manganese hyperaccumulating plant present in New Caledonia. Grevillea exul rubiginosa was collected before flowering, at Col de Mouriange, near Le Mont-Dore, in the Southern province of the subtropical Pacific island of New Caledonia. The leaves were air-dried and ground. The obtained solid $(50 \mathrm{~g})$ was calcined to 400 ${ }^{\circ} \mathrm{C}$ for $5 \mathrm{~h}$ and the resulting ashes $(1.5 \mathrm{~g})$ were added to $20 \mathrm{~mL}$ of a diluted solution of $\mathrm{HCl}(1 \mathrm{M})$. The solution was stirred for $2 \mathrm{~h}$ at 60 ${ }^{\circ} \mathrm{C}$. During the heating, the color of the mixture changed from black to dark green. The reaction mixture was then filtered on a pad of celite. The resulting dark-green solution, composed of different metal chlorides, was concentrated under vacuum, yielding the ecocatalyst Eco- $\mathrm{Mn}^{\mathbb{R}}$ as a pale yellow powder $(2.25 \mathrm{~g})$. Eco-Mn ${ }^{\mathbb{B}}$ was stored in a desiccator under vacuum.

\section{General procedures}

Cyclization of the monoterpene (+)-citronellal into isopulegol isomers

To a suspension of Mn catalyst (amount corresponding to 0.020 $\mathrm{mmol}$ of $\mathrm{Mn}, 2 \mathrm{~mol} \%$ ) in $5 \mathrm{~mL}$ of dichloromethane was added 180.4 $\mu \mathrm{L}$ of $(+)$-citronellal $(1.0 \mathrm{mmol})$. After stirring for $0.5 \mathrm{~h}$ under reflux, the reaction mixture was filtered, washed with a saturated 
aqueous solution of $\mathrm{NaHCO}_{3}$. The organic layer was dried over $\mathrm{Na}_{2} \mathrm{SO}_{4}$, filtered and concentrated under reduced pressure. $95 \%$ of yield and $90 \%$ of (-)-isopulegol stereoselectivity were estimated by GC-MS analysis.

Fourier transform infrared spectroscopy characterization of adsorbed pyridine on catalysts

FTIR measurements were carried out using pyridine as a probe. A PerkinElmer Spectrum100 FT-IR spectrometer was used for recording the spectra. Excess pyridine was adsorbed, then the samples were degassed for $15 \mathrm{~min}$ at $25{ }^{\circ} \mathrm{C}$ (4 mbar) and a first spectrum was recorded. The samples were then degassed for $40 \mathrm{~min}$ at $150{ }^{\circ} \mathrm{C}$ (4 mbar) to eliminate the physisorbed pyridine and a second spectrum was recorded.

Rearrangement of the ethylene acetal of 2-bromopropiophenone

A solution of the ethylene acetal of 2-bromopropiophenone (75.8 $\mathrm{mg}, 0.29 \mathrm{mmol})$ in 1,2-dichlorobenzene $(3.29 \mathrm{~mL})$ was poured onto catalyst (mass corresponding to $0.012 \mathrm{mmol}$ of $\mathrm{Mn}, 4 \mathrm{~mol} \%$ ), with water $(5.31 \mu \mathrm{L}, 0.29 \mathrm{mmol})$. The resulting suspension was magnetically stirred at $180{ }^{\circ} \mathrm{C}$ for $20 \mathrm{~h}$. The mixture reaction was analyzed by GC-MS analysis, with the following temperature program: 4 min isothermal at $80^{\circ} \mathrm{C}$, then increasing from $80^{\circ} \mathrm{C}$ to $270{ }^{\circ} \mathrm{C}$ at $20^{\circ} \mathrm{C} \cdot \mathrm{min}^{-1}$.

\section{Synthesis of HEH}

Paraformaldehyde $(3.0 \mathrm{~g}, 100 \mathrm{mmol})$, ethyl acetoacetate $(50.6 \mathrm{~mL}$, $400 \mathrm{mmol})$ and ammonium acetate $(15.4 \mathrm{~g}, 200 \mathrm{mmol})$ were added to $150 \mathrm{~mL}$ of degasified water. The mixture was vigorously stirred at reflux temperature, under argon atmosphere and away from light (flask protected with aluminum foil), for $2 \mathrm{~h}$. A bright yellow solid precipitated and was collected by filtration after cooling to room temperature. The solid was washed with $20 \mathrm{~mL}$ of water twice and dried in a desiccator under vacuum, avoiding prolonged exposure to light. The obtained solid ( $22.1 \mathrm{~g}, 87 \%$ yield) was nearly pure and used in the next step without further purification.

Test reaction of HEH oxidation in presence of Mn(II) catalysts and water

HEH (253 mg, $1.0 \mathrm{mmol}$ ), Mn(II) catalyst (Mn $1 \mathrm{~mol} \%$ ) and water $(1.8 \mu \mathrm{L}, 10 \mathrm{~mol} \%)$ were introduced into a $4 \mathrm{~mL}$ vial, open to air through a needle. After homogenization with a vortex mixer, the reaction mixture was heated to $110^{\circ} \mathrm{C}, 1 \mathrm{~h}$, under stirring. An aliquot was taken and analyzed in GC-MS after dilution in DCM to determine the proportions of $\mathrm{HEH}$ and corresponding pyridine formed by oxidation.

Reductive amination of ketones by Eco-Mn ${ }^{\circledR} / \mathrm{HEH}$

HEH (278 mg, $1.1 \mathrm{mmol})$, ketone $(1.0 \mathrm{mmol})$, amine $(1.0 \mathrm{mmol})$ and Eco-Mn ${ }^{\circledR}(8.3 \mathrm{mg}, 1 \mathrm{~mol} \% \mathrm{Mn})$ were introduced in a $4 \mathrm{~mL}$ vial. The solid mixture was homogenized with a vortex mixer, and then the reaction mixture was stirred at $110^{\circ} \mathrm{C}$ for $4 \mathrm{~h}$ (the solid melted quickly on heating). After cooling to room temperature, an aliquot was taken and analyzed in GC-MS after dilution in DCM. GC-MS calibration was performed by analysis of known quantities of pure products and biphenyl as internal standard. Products were isolated by flash column chromatography on silica gel (toluene/ethyl acetate, 9:1).

\section{Acknowledgements}

This work was supported by the Agence Nationale de la Recherche (ANR, programme 11ECOT01101), the Agence de l'Environnement et de la Maîtrise de l'Energie (ADEME), the Centre National de la Recherche Scientifique (CNRS) and the Fond Européen de Développement Régional (FEDER).

\section{References}

1. A. J. Hunt, T. J. Farmer and J. H. Clark, in Element Recovery and Sustainability, ed. A. J. Hunt, The Royal Society of Chemistry, Cambridge, 2013, pp. 1-28.

2. K. Salazar, Mineral Commodity Summaries 2013: US Geological Survey (USGS), US Geological Survey, Reston, 2013.

3. L. Lloyd, Handbook of industrial catalysts, Springer Science+Business Media, New York, 2011.

4. A. Kabata-Pendias, Trace elements in soils and plants, CRC Press, Boca Raton, 2011.

5. R. Widmer, H. Oswald-Krapf, D. Sinha-Khetriwal, M. Schnellmann and H. Böni, Environ. Impact Asses., 2005, 25, 436458

6. T. E. Graedel, J. Allwood, J.-P. Birat, M. Buchert, C. Hagelüken, B. Reck, S. Sibley and G. Sonneman, Recycling Rates of Metals A Status Report, A Report of the Working Group on the Global Metal Flows to the International Resource Panel, United Nations Environment Programme (UNEP), 2011.

7. A. Schippers, S. Hedrich, J. Vasters, M. Drobe, W. Sand and S. Willscher, in Geobiotechnology I, eds. A. Schippers, F. Glombitza and W. Sand, Springer Berlin Heidelberg, 2014, vol. 141, ch. 216 pp. $1-47$.

8. H. Brandl, R. Bosshard and M. Wegmann, Hydrometallurgy, 2001, 59, 319-326.

9. J. Cui and E. Forssberg, J. Hazard. Mater., 2003, 99, 243-263.

10. E. Gomez, D. A. Rani, C. R. Cheeseman, D. Deegan, M. Wise and A. R. Boccaccini, J. Hazard. Mater., 2009, 161, 614-626.

11. I. Raskin and B. D. Ensley, Phytoremediation of toxic metals: using plants to clean up the environment, John Wiley, New York, 2000 .

12. C. W. N. Anderson, in Element Recovery and Sustainability, ed. A. J. Hunt, The Royal Society of Chemistry, Cambridge, 2013, pp. 114-139.

13. G. Losfeld, L. L'Huillier, B. Fogliani, T. Jaffré and C. Grison, Environ. Sci. Pollut. Res., 2014, in press 10.1007/s11356-0143358-x.

14. C. M. Grison, M. Mazel, A. Sellini, V. Escande, J. Biton and C. Grison, Environ. Sci. Pollut. Res., 2014, in press 10.1007/s11356014-3605-1.

G. Losfeld, L. L'Huillier, B. Fogliani, S. Coy, C. Grison and T. Jaffré, Environ. Sci. Pollut. Res., 2014, in press 10.1007/s11356 014-3445-z.

16. O. V. Singh, S. Labana, G. Pandey, R. Budhiraja and R. K. Jain, Appl. Microbiol. Biotechnol., 2003, 61, 405-412.

17. A. Bhargava, F. F. Carmona, M. Bhargava and S. Srivastava, $J$ Environ. Manage., 2012, 105, 103-120.

18. Fr. Pat., PCT/FR2009/052312; WO 2011064462 A1 20110603 , 2011.

19. G. Losfeld, P. V. de la Blache, V. Escande and C. Grison, Green Chem. Lett. Rev., 2012, 5, 451-456.

20. C. Grison, V. Escande, E. Petit, L. Garoux, C. Boulanger and C. Grison, RSC Adv., 2013, 3, 22340-22345.

21. V. Escande, L. Garoux, C. Grison, Y. Thillier, F. Debart, J. J. Vasseur, C. Boulanger and C. Grison, Appl. Catal., B, 2014, 146 279-288.

22. P. Anastas and J. C. Warner, in Green Chemistry: Theory and Practice, Oxford University Press, Oxford, 1998, ch. 10, p. 117.

23. V. Escande, T. K. Olszewski, E. Petit and C. Grison ChemSusChem, 2014, 7, 1915-1923.

24. V. Escande, T. Olszewski and C. Grison, Environ. Sci. Pollut. Res., 2014, in press 10.1007/s11356-014-3483-6.

25. V. Escande, A. Velati and C. Grison, Environ. Sci. Pollut. Res. 2014, in press $10.1007 /$ s11356-014-3433-3.

26. V. Escande, T. K. Olszewski and C. Grison, C. R. Chim., 2014 17, 731-737.

27. V. Escande, B.-L. Renard and C. Grison, Environ. Sci. Pollut Res., 2014, in press 10.1007/s11356-014-3631-Z. 
G. Losfeld, V. Escande, T. Jaffré, L. L'Huillier and C. Grison, Chemosphere, 2012, 89, 907-910.

G. Losfeld, V. Escande, P. V. de La Blache, L. L'Huillier and C. Grison, Catal. Today, 2012, 189, 111-116.

Fr. Pat., EP2769765A1, 2013.

Fr. Pat., WO 2014016509 A1 20140130, 2014.

M. Sankar, N. Dimitratos, P. J. Miedziak, P. P. Wells, C. J. Kiely and G. J. Hutchings, Chem. Soc. Rev., 2012, 41, 8099-8139.

N. N. Greenwood and A. Earnshaw, in Chemistry of the elements, Butterworth-Heinemann, Oxford ; Boston, 2nd edn., 1997, pp. 1040-1069.

G. B. Gerber, A. Léonard and P. Hantson, Crit. Rev. Oncol. Hematol., 2002, 42, 25-34.

D. Arndt and D. G. Lee, Manganese compounds as oxidizing agents in organic chemistry, Open Court Pub. Co., La Salle, 1981. W. R. Browne, J. W. De Boer, D. Pijper, J. Brinksma, R. Hage and B. L. Feringa, in Modern oxidation methods, ed. J.-E. Bäckvall, Wiley-VCH, Weinheim, 2nd edn., 2010, pp. 371-420. D. G. Lee, in The Chemistry of Organomanganese Compounds, eds. Z. Rappoport and I. Marek, John Wiley \& Sons Ltd, Chichester, 2010, ch. 19, pp. 419-488.

S. Gomez, J. A. Peters and T. Maschmeyer, Adv. Synth. Catal., 2002, 344, 1037-1057.

R. P. Tripathi, S. S. Verma, J. Pandey and V. K. Tiwari, Curr. Org. Chem., 2008, 12, 1093-1115.

T. C. Nugent and M. El-Shazly, Adv. Synth. Catal., 2010, 352, 753-819.

A. F. Abdel-Magid, Reductions in organic synthesis : recent advances and practical applications, American Chemical Society, Washington, DC, 1996.

P. G. Andersson and I. J. Munslow, Modern reduction methods, Wiley-VCH, Weinheim, 2008.

E. W. Baxter and A. B. Reitz, in Organic Reactions, John Wiley \& Sons, Hoboken, 2002, vol. 59, ch. Reductive Aminations of Carbonyl Compounds with Borohydride and Borane Reducing Agents, pp. 1-714.

J. A. Moore and Expert Scientific Committee, Reprod. Toxicol., 1997, 11, 123-160.

P. A. Fail, R. E. Chapin, C. J. Price and J. J. Heindel, Reprod. Toxicol., 1998, 12, 1-18.

European Chemicals Agency (ECHA), Candidate List of Substances of Very High Concern for Authorisation, http://echa.europa.eu/candidate-list-table, Accessed October 29, 2014.

C. L. Barney, E. V. Huber and J. R. McCarthy, Tetrahedron Lett., 1990, 31, 5547-5550.

A. F. Abdel-Magid and S. J. Mehrman, Org. Process Res. Dev., 2006, 10, 971-1031.

A. Pelter, R. M. Rosser and S. Mills, J. Chem. Soc., Perkin Trans. 1, 1984, 717-720.

S. Chandrasekhar, C. R. Reddy and M. Ahmed, Synlett, 2000, 1655-1657.

R. Apodaca and W. Xiao, Org. Lett., 2001, 3, 1745-1748.

C. Wang, A. Pettman, J. Basca and J. L. Xiao, Angew. Chem., Int. Ed., 2010, 49, 7548-7552.

R. Kadyrov and T. H. Riermeier, Angew. Chem., Int. Ed., 2003, 42, 5472-5474

C. Zheng and S. L. You, Chem. Soc. Rev., 2012, 41, 2498-2518.

W. S. Bechara and A. B. Charette, in e-EROS Encyclopedia of Reagents for Organic Synthesis, John Wiley \& Sons, 2011, ch. Diethyl 1,4-Dihydro-2,6-dimethyl-3,5-pyridinedicarboxylate.

J. B. Steevens and U. K. Pandit, Tetrahedron, 1983, 39, 13951400 .

Z. G. Liu, N. Li, L. Yang, Z. L. Liu and W. Yu, Chin. Chem. Lett., 2007, 18, 458-460.

T. Itoh, K. Nagata, M. Miyazaki, H. Ishikawa, A. Kurihara and A. Ohsawa, Tetrahedron, 2004, 60, 6649-6655.

M. Zhang, H. W. Yang, Y. Zhang, C. J. Zhu, W. Li, Y. X. Cheng and H. W. Hu, Chem. Commun., 2011, 47, 6605-6607.

A. Kumar, S. Sharma and R. A. Maurya, Adv. Synth. Catal., 2010, 352, 2227-2232.

S. Hoffmann, M. Nicoletti and B. List, J. Am. Chem. Soc., 2006, 128, 13074-13075.

V. N. Wakchaure, J. A. Zhou, S. Hoffmann and B. List, Angew. Chem., Int. Ed., 2010, 49, 4612-4614. 2005, 44, 7424-7427.

R. I. Storer, D. E. Carrera, Y. Ni and D. W. C. MacMillan, J. Am. Chem. Soc., 2006, 128, 84-86.
D. Menche, F. Arikan, J. Li, S. Rudolph and F. Sasse, Biorg. Med. Chem., 2007, 15, 7311-7317.

D. Menche, S. Bohm, J. Li, S. Rudolph and W. Zander Tetrahedron Lett., 2007, 48, 365-369.

$68 . \quad$ D. Menche, J. Hassfeld, J. Li, G. Menche, A. Ritter and S. Rudolph, Org. Lett., 2006, 8, 741-744.

69. P. B. N. Quynh and T. H. Kim, Synthesis, 2012, 44, 1977-1982.

70. Y. B. Huang, W. B. Yi and C. Cai, J. Fluorine Chem., 2010, 131, 879-882.

71. J. P. Adams, C. M. Alder, I. Andrews, A. M. Bullion, M Campbell-Crawford, M. G. Darcy, J. D. Hayler, R. K. Henderson, C. A. Oare, I. Pendrak, A. M. Redman, L. E. Shuster, H. F. Sneddon and M. D. Walker, Green Chem., 2013, 15, 1542-1549.

C. Grison, Environ. Sci. Pollut. Res., 2014, in press 10.1007/s11356-014-3169-0.

73. G. Losfeld, R. Mathieu, L. L'Huillier, B. Fogliani, T. Jaffré and C. Grison, Environ. Sci. Pollut. Res., 2014, in press 10.1007/s11356-014-3866-8.

74. F. Feigl and V. Anger, Spot tests in inorganic analysis, Elsevie Pub. Co., Amsterdam, New York, 1972.

L. Alaerts, E. Seguin, H. Poelman, F. Thibault-Starzyk, P. A. Jacobs and D. E. De Vos, Chem. Eur. J., 2006, 12, 7353-7363.

M. Vandichel, F. Vermoortele, S. Cottenie, D. E. De Vos, M Waroquier and V. Van Speybroeck, J. Catal., 2013, 305, 118-129. S. Imachi, K. Owada and M. Onaka, J. Mol. Catal. A: Chem., 2007, 272, 174-181.

P. J. Kropp, G. W. Breton, S. L. Craig, S. D. Crawford, W. F. Durland, J. E. Jones and J. S. Raleigh, J. Org. Chem., 1995, 60, 4146-4152.

79.

C. Milone, C. Gangemi, G. Neri, A. Pistone and S. Galvagno, Appl. Catal., A, 2000, 199, 239-244.

Y. Nakatani and K. Kawashima, Synthesis, 1978, 147-148.

E. P. Parry, J. Catal., 1963, 2, 371-379.

M. I. Zaki, M. A. Hasan, F. A. Al-Sagheer and L. Pasupulety, Colloid. Surface A, 2001, 190, 261-274.

A. Corma, H. Garcia, A. Primo and A. Domenech, New J. Chem., 2004, 28, 361-365.

M. V. Baldovi, A. Corma, V. Fornes, H. Garcia, A. Martinez and J. Primo, J. Chem. Soc., Chem. Commun., 1992, 949-951.

R. G. Pearson, J. Chem. Educ., 1968, 45, 581-587.

R. G. Pearson, Inorg. Chim. Acta, 1995, 240, 93-98.

T.-L. Ho, Chem. Rev., 1975, 75, 1-20.

G. W. Wang, J. J. Xia, C. B. Miao and X. L. Wu, Bull. Chem. Soc. Jpn., 2006, 79, 454-459.

H. Remarian and A. Mirjafari, Biorg. Med. Chem. Lett., 2005 , 15, 3423-3425.

90. Q. P. B. Nguyen and T. H. Kim, Tetrahedron, 2013, 69, 49384943.

91. R. C. Erd, M. A. Clynne, J. R. Clark and R. W. Potter, II, J. Appl. Crystallogr., 1979, 12, 481-482.

92. D. B. Bagal, R. A. Watile, M. V. Khedkar, K. P. Dhake and B. M. Bhanage, Catal. Sci. Technol., 2012, 2, 354-358.

93.

J. Deng, L.-P. Mo, F.-Y. Zhao, L.-L. Hou, L. Yang and Z.-H Zhang, Green Chem., 2011, 13, 2576-2584.

S. Kim, C. H. Oh, J. S. Ko, K. H. Ahn and Y. J. Kim, J. Org. Chem., 1985, 50, 1927-1932.

95. S. Werkmeister, K. Junge and M. Beller, Green Chem., 2012, 14, 2371-2374.

96. M. Mirza-Aghayan, M. M. Tavana, M. Rahimifard and R. Boukherroub, Appl. Organomet. Chem., 2014, 28, 113-115.

97. V. Ravi, E. Ramu, P. Vijay kumar and A. Srinivas rao, Chin. J. Chem . 2006, 24, 807-810.

P. Vaneikeren and D. L. Grier, J. Am. Chem. Soc., 1976, 98, 4655-4657.

P. Vaneikeren, D. L. Grier and J. Eliason, J. Am. Chem. Soc., 1979, 101, 7406-7409.

100. R. Srinivasan, R. T. Medary, H. F. Fisher, D. J. Norris and R. Stewart, J. Am. Chem. Soc., 1982, 104, 807-812.

101. B. Yao, H. T. Ji, Y. B. Cao, Y. J. Zhou, J. Zhu, J. G. Lu, Y. W. Li, J. Chen, C. H. Zheng, Y. Y. Jiang, R. M. Liang and H. Tang, $J$. Med. Chem., 2007, 50, 5293-5300.

102. US Pat., WO2008/011161A2, 2006.

103. US Pat., WO2012/112969A1, 2011. 